\title{
Oxygen semipermeable solid oxide membrane composites prepared by electrochemical vapor deposition
}

\author{
Y.S. Lin, K.J. de Vries, H.W. Brinkman and A.J. Burggraaf \\ Laboratory of Inorganic Chemistry, Materials Science and Catalysis, Department of Chemical Technology, University of \\ Twente, P.O. Box 217, 7500 AE Enschede (Netherlands)
}

(Received June 10, 1991; accepted in revised form September 30, 1991)

\begin{abstract}
Ceramic membrane composites consisting of a coarse porous $\alpha$-alumina or two-layer porous alumina membrane support and an oxygen semipermeable gas tight thin $(0.2-5 \mu \mathrm{m})$ yttria stabilized zirconia (YSZ) film are prepared by the electrochemical vapor deposition (EVD) method. The minimum gastight thickness of the YSZ films depends strongly on the average pore size of the support on which the films are deposited by the EVD process. The oxygen permeation fluxes through such gas tight YSZ membrane composites, measured in situ on the EVD apparatus, are in the range of $3 \times 10^{-9}$ to $6 \times 10^{-8}$ $\mathrm{mol} / \mathrm{cm}^{2}$-sec with an oxygen partial pressures of $P_{\mathrm{O}_{2}}^{\prime}$ (high) $\approx 3 \times 10^{-2}$ atm and $P_{\mathrm{O}_{2}}^{\prime \prime}$ (low) $\approx 10^{-5} \mathrm{~atm}$, much larger than the literature data for thicker YSZ pellets. During the oxygen permeation experiments the rate-limiting step is found to be the bulk electrochemical transport in the grown YSZ films with a thickness smaller than $10 \mu \mathrm{m}$.
\end{abstract}

Keywords: yttria stabilized zirconia; solid oxide membrane composites; oxygen permeation; electrochemical vapor deposition; ceramic membranes

\section{Introduction}

Ceramic membrane composites with an impervious but oxygen permeable thin dense electrolyte film can be used in solid oxide fuel cells, catalytic membrane reactors, gas sensors and oxygen membrane separators, and therefore are of great importance in chemical, environmental and energy conversion industries. The most interesting materials which can be used to make the oxygen semipermeable membrane films are fast ionic conductors (e.g. yttria stabilized zir-

Correspondence to: Y.S. Lin, Department of Chemical Engineering, 629 Rhodes Hall (ML 171), University of Cincinnati, Cincinnati, OH 45221-0171, USA. conia, YSZ) or fast mixed conductors (e.g. some perovskite type materials) because they are highly selective for oxygen transport [1]. The major challenge in preparation of these oxygen permeable membranes is the fabrication of a very thin gas-tight film of these inorganic crystalline materials supported by a porous support (which provides mechanical strength). An oxygen semipermeable solid oxide membrane film should be as thin as possible in order to maximize the oxygen permeation flux since the electrochemical transport resistance is, in many cases, proportional to the film thickness. Very thin films can be fabricated without difficulty from glassy or polymeric materials but not as 
easily from the inorganic crystalline materials of solid oxides.

Recent developments in the electrochemical vapor deposition (EVD) technique, originally developed by Westinghouse Electric Co. [2] for fabrication of gas-tight solid electrolyte films for fuel cell applications, showed that it is possible to use this technique for the manufacture of oxygen semipermeable membrane composites with an ultrathin solid oxide electrolyte film. In the EVD process, a porous substrate (as the support in the membrane composite) separates a mixture of two to three metal chloride vapors and an oxygen source reactant (water vapor or oxygen). Initially, in the socalled chemical vapor deposition (CVD) stage of the EVD process, the reactants from both sides of the substrate inter-diffuse into the substrate pores and react to form a solid solution of oxides deposited on the internal pore surface of the substrate. This solid deposit can eventually plug the substrate pore entrance in the surface of the substrate exposed to the chloride vapors under certain conditions $[3,4]$, resulting in a physical barrier which prevents direct contact of the reactants on both sides of substrate. Since the deposit is an oxygen permeable solid oxide, an oxide film can then grow on the surface of the substrate in the chloride side by the Wagner scaling process $[5,6]$. The unique feature of the EVD technique is its ability to make a gas-tight electrolyte film on a porous support since the residual pores or pinholes, if there are any, can be plugged by the deposited oxides due to direct contact between the reactants in the residual pore openings.

Previous studies on the EVD process focused on the growth of YSZ, films with a thickness ranging from 5 to $50 \mu \mathrm{m}$ on porous substrates [2,7-10]. For solid oxide fuel cells the thickness of the electrolyte in this range is acceptable as long as the reduction of the ohmic loss (due to the ionic conducting resistance) in the electrolyte is at a negligible level compared to the resistance in the electrodes. For oxygen semipermeable membranes, a further decrease of the electrolyte film thickness ( $>1 \mu \mathrm{m}$ ) with a sufficiently large surface oxygen exchange rate would be interesting in order to obtain a maximum oxygen permeation flux. Fabrication of such very thin gas-tight electrolyte films supported on porous substrates has not been found to be reported before.

In order to better understand the EVD process, some theoretical and experimental work has been carried out to investigate the kinetics of the EVD film growing process [8-11]. Carolan and Michaels [8] and some other investigators $[9,10]$ reported theoretical analyses, with some experimental results, of the growth of YSZ film on porous substrates by the EVD method. Only electrochemical transport in the bulk metal oxide film was considered. Following almost the identical procedure as employed for deriving the thickness-time relation for the Wagner scaling process $[5,6]$, they found that the EVD kinetics can be described by the parabolic law (the film thickness is proportional to the square root of the deposition time) with a parabolic rate constant determined only by the free-electronic conductivity $[8,9]$ or together with the electronic-hole conductivity [10]. Observing some other experimental evidences on the EVD film growth data that can not be explained by the parabolic law, Lin et al. [11] recently reported a more systematic theoretical and experimental study on the EVD kinetics. They found that the EVD process involves four oxygen transport steps: (1) diffusion of oxygen reactant in the substrate pores (pore diffusion step); (2) reduction charge transfer reaction at the oxygen/EVD film interface (reduction surface reaction step); (3) electrochemical transport of oxygen ions and electrons in the EVD film (bulk diffusion step); and (4) oxidation charge transfer reaction at the interface of the EVD film/metal chloride vapor (oxidation surface reaction 
step). Lin et al. [11] showed that either the pore diffusion step or the bulk diffusion step can be rate limiting in the EVD film growing process, depending on the deposition conditions such as substrate pore dimension, deposition temperature and pressure.

Oxygen permeation through the membrane composites prepared by the EVD method should, in principle, follow a similar mechanism as involved in the EVD film growing process: pore diffusion, reduction surface reaction, bulk diffusion and oxidation surface reaction. Among the limited number of studies on the oxygen permeation through YSZ, most researchers [12-15] considered only the bulk diffusion in the electrolyte film and found that the oxygen permeation flux is reversily proportional to the electrolyte thickness. They also found experimentally that the dependency of the oxygen permeation flux on the oxygen partial pressure is $P_{\mathrm{O}_{2}}^{-1 / 4}$ at lower $P_{\mathrm{O}_{2}}$ and $P_{\mathrm{O}_{2}}^{1 / 4}$ at higher $P_{\mathrm{O}_{2}}$, which is consistent with the theoretical prediction assuming the bulk diffusion as being the rate-limiting step. Dou et al. [16] investigated the oxygen permeation in calciastabilized zirconia films and considered both the reduction surface reaction step and the bulk diffusion step. They predicted, based on the oxygen permeation data on thicker $(\geqslant 500 \mu \mathrm{m})$ calcia-stabilized zirconia pellets, that a transition from the bulk diffusion rate-control to the surface reaction rate-control occurs when the thickness of a calcia-stabilized zirconia sample gets smaller than $270 \mu \mathrm{m}$ at $1 \mathrm{~atm}$ of oxygen partial pressure.

In the previous study [11], Lin et al. found that the YSZ film growth rate (with a YSZ film thickness of ca. 1 to $5 \mu \mathrm{m}$ ) during the EVD process is equivalent to an oxygen permeation flux which is several orders of magnitude larger than the value predicted using the surface reaction rate coefficients reported by Dou et al. [16]. This suggests that the prediction of the range of the film thicknesses for the surface reaction rate-control made by Dou et al. [16] may not apply to the YSZ films prepared by EVD because of the possible effects of different crystallite size, much smaller film thickness $(<10$ $\mu \mathrm{m})$ and different $P_{\mathrm{O}_{2}}$ range. Therefore, investigation of the oxygen permeation through the YSZ film prepared by EVD is of great importance in understanding the oxygen permeation mechanism through very thin electrolyte films. In current literature, however, there are no experimental studies reported on the oxygen permeation through stabilized zirconia films with a thickness smaller than $500 \mu \mathrm{m}$, due to unavailability of such thin gas-tight electrolyte films supported on porous substrate and difficulties associated with sealing the thin electrolyte films on a permeation cell at high temperatures for the permeation measurements. Furthermore, the previous oxygen permeation work was all performed on stabilized zirconia thin pellets prepared by the conventional ceramic powder-sintering process. No oxygen permeation data on the electrolyte films prepared by the EVD method is available in the open literature. The main objectives of this paper are to report the EVD preparation of ceramic membrane composites consisting of a thin YSZ film with a thickness in the micrometer or nanometer scale and the oxygen permeation through such gas-tight ceramic membrane composites.

\section{Experimental}

The EVD experiments were performed in a home-built EVD apparatus consisting of a central reactor, water vapor delivery, metal chloride vapor delivery and vacuum systems. The central reactor was made of three dense alumina tubes of different size. A porous substrate was cemented onto the end of the smaller tube, separating the reactor into two chambers, as depicted in Fig. 1(A) which schematically shows the smallest and medium alumina tubes 

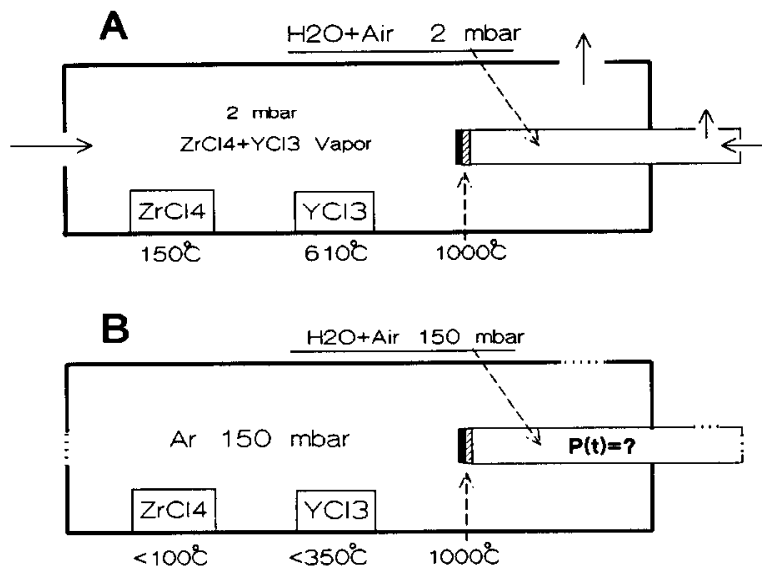

Fig. 1. Schematic representation of the central EVD reactor during the film growing experiments (A) and the oxygen permeation experiments (B).

of the central reactor. The $\mathrm{ZrCl}_{4}$ and $\mathrm{YCl}_{3}$ sublimation beds were placed inside the medium tube. The temperatures of the sublimation beds and substrate were controlled by a six-zone heating element surrounding the largest dense alumina tube which was coaxially placed outside of the medium tube (not shown in the figure). In the EVD experiments, water vapor carried by air or other oxygen source reactant was introduced into the smallest tube (referred to as the oxygen-chamber) and the chloride vapors were generated in the medium tube (referred to as the chloride-chamber) by passing Ar through the sublimation beds. The volume of the oxygen-chamber $(375 \mathrm{ml})$ was about 20 times smaller than that of the chloride-chamber $(8030 \mathrm{ml})$. The details on the EVD apparatus are given elsewhere $[17,18]$.

The following two types of disk-shaped ceramic substrates (12 $\mathrm{mm}$ in diameter and ca. 2 $\mathrm{mm}$ in thickness ) were used in the EVD experiments: (A) coarse porous $\alpha$-alumina and (B) two-layer alumina membrane composites. The coarse porous substrates had an average pore diameter of $0.2 \mu \mathrm{m}$ and porosity of $50 \%$. The membrane substrates were prepared by coating a thin film of thermal stability improved $\gamma$-al- umina on the coarse porous alumina substrates using the sol-gel method [19]. The top-layer of the membrane substrates had an average pore diameter of $10 \mathrm{~nm}$ and a thickness of ca. $3 \mu \mathrm{m}$ and was thermally stable at $1000^{\circ} \mathrm{C}$. Pore size distributions of the coarse porous substrates and the top-layer of the membrane substrate are shown in Fig. 2. In the EVD experiments, a membrane substrate disk was cemented onto the smallest tube in the central reactor with its top-layer facing the chloride-chamber.

The deposition experiments were performed in the EVD reactor with a total pressure of 2 mbar at both the chloride- and oxygen-chambers through which the gas-flows containing the chloride vapors and water vapor were constantly passed, as shown in Fig. 1(A). During deposition, the sublimation beds and substrate were kept at the given temperatures. Typical experimental conditions for growing YSZ film are listed in Table 1. After a given period of time of deposition (typically 20-100 min), the EVD film growing process was terminated by shutting off the oxygen containing flow. Gas tightness of a substrate after deposition was checked by Ar permeation through the substrate at the

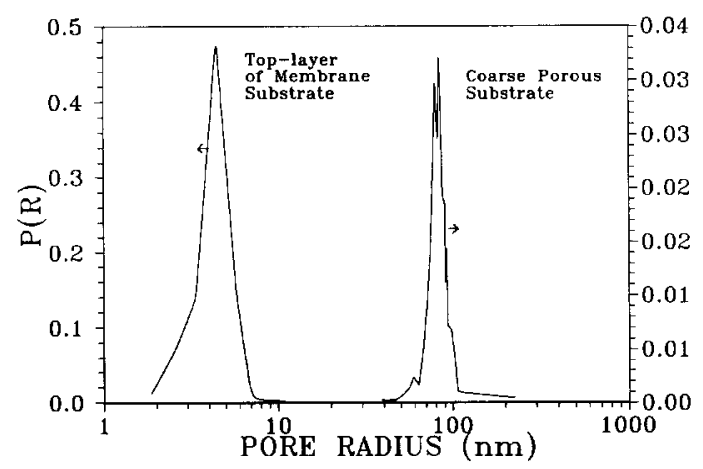

Fig. 2. Normalized pore size distributions of the coarse porous substrate (by mercury porosimetry) and the top-layer of the membrane substrate (by nitrogen adsorption porosimetry) $[P(r) \mathrm{d} r$ has a physical meaning of the volume of the pores with a pore radius from $r$ to $r+\mathrm{d} r$ to the total volume of the all pores]. 
TABLE 1

Typical experimental conditions

EVD film growing experiments

Deposition temperature

$\mathrm{ZrCl}_{4}$ sublimation temperature

$\mathrm{YCl}_{3}$ sublimation temperature

$\mathrm{YCl}_{3} / \mathrm{ZrCl}_{4}$ vapor (mole) ratio

Total pressure

$\mathrm{ZrCl}_{4}$ vapor concentration

Water vapor concentration

Water vapor/air (volume) ratio

$P_{\mathrm{O}_{2}}$ in chloride chamber

$P_{\mathrm{O}_{2}}$ in oxygen chamber (with air/steam)

Oxygen permeation experiments

Total pressure in chloride chamber

Total pressure in the oxygen chamber

Permeation temperature

$P_{\mathrm{O}_{2}}$ in chloride chamber

$P_{\mathrm{O}_{2}}$ in oxygen chamber

$$
\begin{aligned}
& 1000^{\circ} \mathrm{C} \\
& 150^{\circ} \mathrm{C} \\
& 613^{\circ} \mathrm{C} \\
& 1 / 5 \\
& 2 \mathrm{mbar}\left(1.97 \times 10^{-3} \mathrm{~atm}\right) \\
& 3.5 \times 10^{-9} \mathrm{~mol} / \mathrm{cm}^{3} \\
& 2.0 \times 10^{-9} \mathrm{~mol} / \mathrm{cm}^{3} \\
& 2 / 3-1.1 \\
& <10^{-14} \text { atm } \\
& 6 \times 10^{-4} \text { atm } \\
& 150 \mathrm{mbar}(0.148 \mathrm{~atm}) \\
& 150 \mathrm{mbar}(0.148 \mathrm{~atm}) \\
& 1000^{\circ} \mathrm{C} \\
& \sim 10^{-5} \text { atm } \\
& <3 \times 10^{-2} \mathrm{~atm}
\end{aligned}
$$

${ }^{\text {a}}$ Estimated from the purity of Ar gas filled in the chloride chamber.

deposition temperature. This was done by measuring pressure increase in the oxygenchamber initially filled with Ar at 100 mbar and isolated by closing all the inlet and outlet valves, with a constant pressure of 200 mbar in the chloride-chamber filled with Ar. The Ar permeability for the substrate (after deposition) of more than 200 times smaller than that for the same substrate before deposition was used to roughly indicate the gas tightness. For some substrates after deposition, gas tightness was more accurately checked by measuring the permeability in a home-built permeation measurement unit at room temperature. The thickness and phase structure of grown zirconia/yttria films were examined by SEM (Jeol JSM-35 CF) and XRD (Philips PW 1710, Ni-filtered $\mathrm{Cu}-\mathrm{K} \alpha$ ).

The oxygen permeation measurements on the ceramic membrane composites consisting of a thin YSZ film grown by the EVD method were performed in the EVD apparatus after the EVD film growing process. Since the EVD is a selfpore-plugging process, even pores or pinholes in the sealing region between the edge of the substrate disk and the internal surface of the end part of the smallest tube were also filled by the deposit during the deposition step. Therefore the substrate was gas tight in the reactor after deposition. This way of in-situ oxygen permeation measurement avoided the hightemperature sealing problem and other difficulties associated with measuring the oxygen permeation through these membrane composites using a special permeation apparatus.

In the in-situ oxygen permeation measurements, the temperature of a substrate after deposition was kept at a temperature similar to that for deposition $\left(950-1050^{\circ} \mathrm{C}\right)$. The sublimation beds were cooled down to $100^{\circ} \mathrm{C}$ or lower for $\mathrm{ZrCl}_{4}$ and $350^{\circ} \mathrm{C}$ or lower for $\mathrm{YCl}_{3}$ to minimize the vapor pressure of the chloride. This was done to reduce the possible growth of the YSZ film during oxygen permeation measurements. This precaution may not have been completely sufficient. A permeation experiment was started by flushing the oxygen-chamber with an oxygen containing gas and the chlo- 
ride-chamber with Ar for at least five minutes. The chloride-chamber was filled with high purity Ar and the oxygen-chamber with air or air/ steam, both to a total pressure of $150 \mathrm{mbar}$ $(0.148 \mathrm{~atm})$. Both the reactor chambers were isolated by closing all the inlet and outlet valves and the total pressure change in the oxygenchamber was monitored (by a personal computer), as shown in Fig. 1B. Before each permeation measurement, a blank run was performed with both reactor chambers filled initially with Ar at 150 mbar to check possible leakage through the closed inlet and outlet valves. Typical experimental conditions for the oxygen permeation measurements are also given in Table 1. Figure 3 gives an example of the pressure change as function of time in the oxygen-chamber filled with Ar, air and air/ steam. The slopes of the pressure change data are used to calculate the permeation flux (or leakage flux). There is a slight leakage through the closed valves connected to the vacuum pump, as indicated by the small slope of the pressure change data for Ar shown in Fig. 3. The fact that the pressure drop in the oxygenchamber when filled with air or air/steam is much more substantial than when filled with Ar indicates a considerable amount of oxygen flux permeating through the EVD prepared membrane composite. The oxygen permeation flux was calculated from the slopes of the pres-

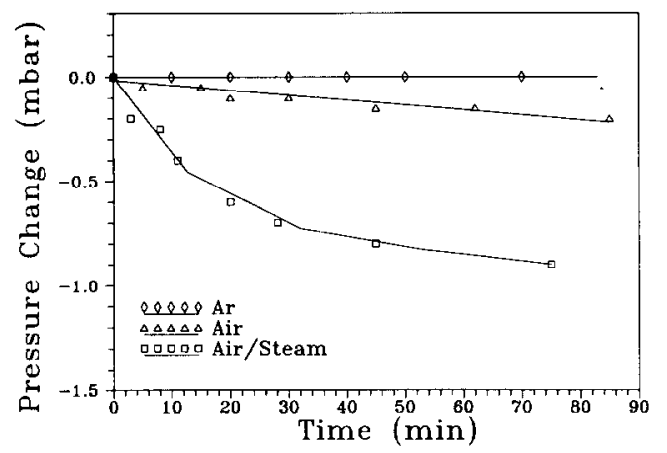

Fig. 3. Pressure change in the oxygen-chamber as a function of time during oxygen permeation measurements. sure change data of air or air/vapor from which the slope of the blank run was subtracted.

\section{Results and discussion}

\section{YSZ film growth}

Gas-tight YSZ films of $2-8 \mu \mathrm{m}$ in thickness were grown on the coarse porous substrates. It is difficult, however, to grow gas-tight YSZ films with a thickness smaller than $1 \mu \mathrm{m}$ on the coarse porous substrates due, probably, to the larger average pore size of the coarse porous substrates. The gas-tightness was proven by zero He flux with a 4 bar pressure drop across the EVD prepared membrane composite measured at room temperature with the special permeation apparatus. The YSZ films grown on the coarse porous substrates remain gas-tight after three thermal cyclings between room temperature and $1000^{\circ} \mathrm{C}$ with a heating or cooling rate of $180^{\circ} \mathrm{C} / \mathrm{hr}$.

As reported in the previous study [11], the rate-limiting step for the EVD film growth pro-

\section{TABLE 2}

Effects of reactant partial pressures on YSZ film growth rate $^{\mathrm{a}}$

\begin{tabular}{lll}
$\begin{array}{l}\text { Effects of } P_{\mathrm{O}_{2}} \\
\begin{array}{l}\text { Oxygen source } \\
\text { reactant }\end{array}\end{array}$ & $\begin{array}{l}P_{\mathrm{O}_{2}} \\
(\mathrm{~atm})\end{array}$ & $\begin{array}{l}\text { Growth rate } \\
(\mu \mathrm{m} / \mathrm{hr})\end{array}$ \\
\hline $\mathrm{Air} / \mathrm{H}_{2} \mathrm{O}(1: 1)$ & $10^{-4}$ & $\sim 1.5$ \\
$\mathrm{O}_{2} / \mathrm{H}_{2} \mathrm{O}(1: 1)$ & $10^{-3}$ & $\sim 1.5$ \\
$\mathrm{H}_{2} / \mathrm{H}_{2} \mathrm{O}(2: 3)$ & $10^{-14}$ & $1.2-1.6$ \\
Dried air or $\mathrm{O}_{2}$ & $10^{-4}$ & $<0.5$ \\
\hline Effects of $P_{\mathrm{ZrCl}}$ & & \\
$T_{\mathrm{ZrCl}}\left({ }^{\circ} \mathrm{C}\right)$ & $P_{\mathrm{ZrCl}}$ & $\begin{array}{l}\mathrm{Growth} \text { rate } \\
(\mu \mathrm{m} / \mathrm{hr})\end{array}$ \\
\hline 140 & $(\mathrm{~atm})$ & $(\mu \mathrm{m}$ \\
150 & $6.4 \times 10^{-5}$ & 2.0 \\
160 & $1.3 \times 10^{-4}$ & 1.5 \\
180 & $2.6 \times 10^{-4}$ & 1.7 \\
& $9.2 \times 10^{-4}$ & 1.5
\end{tabular}

${ }^{\text {a }}$ Values of all other parameters are the same as listed in Table 1 for EVD film growing. 

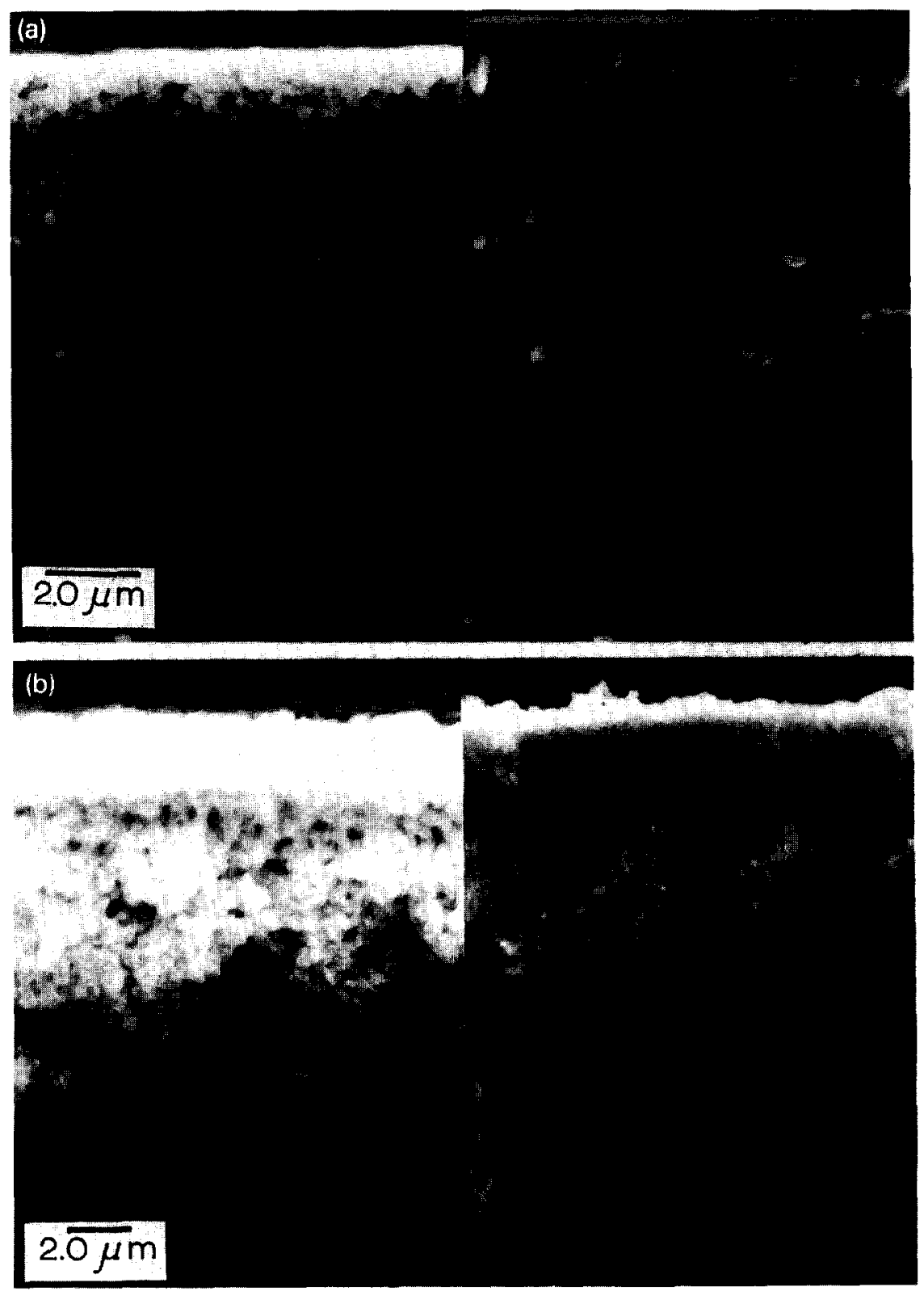

Fig. 4. SEM photographs of YSZ films grown at $700^{\circ} \mathrm{C}$ (a) and $1000^{\circ} \mathrm{C}$ (b) on the coarse porous substrates (Left: backscattered electron image; Right: secondary electron image).

cess on the coarse porous substrates is the diffusion of the oxygen source reactant in the substrate pores under the deposition conditions (especially at low total pressure, e.g. 2 mbar).
An average YSZ film growth rate of $1.5 \mu \mathrm{m} / \mathrm{hr}$ at $1000^{\circ} \mathrm{C}$ was found on the coarse porous substrates, consistent with the oxygen diffusion flux rate in the substrate pores. The YSZ film 
growth rates on the coarse porous substrates under the deposition conditions of different $x$ ygen partial pressure in the oxygen-chamber and different (zirconium) chloride vapor pressure in the chloride-chamber are summarized in Table 2 to examine the effects of the reactant concentrations on the YSZ film growth rates. The results show that both the oxygen partial pressure, in the studied range of $10^{-14}$ to $10^{-3}$ atm, and the chloride vapor pressure have negligible effects on the film growth rates. Since the rate-limiting step is diffusion of the oxygen source reactant (oxygen or $\mathrm{H}_{2} \mathrm{O}$ ) in the pores, the film growth rate is determined by the partial pressure of the oxygen source reactant (all ca. $5 \times 10^{-4} \mathrm{~atm}$ ), and the substrate pore dimension. The results given in Table 2 suggest that the pore diffusion step is the rate-limiting step under the current experimental conditions.

Deposition of YSZ on the coarse pore substrates was also performed at different deposition temperatures $\left(700-1000^{\circ} \mathrm{C}\right)$ to study the effects of temperature on the film growth rate. SEM photographs of the cross-sections of two substrates after deposition at $700^{\circ} \mathrm{C}$ and $1000^{\circ} \mathrm{C}$ are compared in Fig. 4 where in both cases a YSZ film can be seen on the top of each substrate. The film thickness estimated from the SEM photographs for several substrates (including the two shown in Fig. 4) after deposition at different temperatures are given in Table 3. Because YSZ was deposited on/in the rather coarse ceramic substrates, the estimated values of the film thickness from the SEM photographs should not be considered as very accurate ones especially for the samples after deposition at the lower temperatures. To provide further information on the deposition results, $\mathrm{XRD}$ analysis was also performed on these samples after deposition. Figure 5 shows the XRD patterns for the substrate after deposition at $700^{\circ} \mathrm{C}$. Table 3 also lists values of the ratio $R$ of the XRD intensity of the reflection from the (111) plane of the deposited cubic
TABLE 3

Effects of deposition temperature on the YSZ film growth rate $^{\mathrm{a}}$

\begin{tabular}{lll}
\hline $\begin{array}{l}\text { Deposition } \\
\text { temp. }\left({ }^{\circ} \mathrm{C}\right)\end{array}$ & $\begin{array}{l}\text { Estimated film } \\
\text { thickness } \\
(\mu \mathrm{m})\end{array}$ & $I \mathrm{c}(111) / I \alpha(012)^{\mathrm{b}}$ \\
\hline 700 & 1 & 0.2 \\
900 & 1.2 & 0.3 \\
850 & 1.2 & 0.8 \\
900 & 1.3 & 3.8 \\
950 & 1.3 & 11 \\
1000 & 3.0 & 22 \\
\hline
\end{tabular}

Total deposition time 90-95 min; pore-closure time 30-45 min.

${ }^{b}$ Ratio of XRD intensity for the reflection from cubic YSZ (111) to that from $\alpha$-alumina (substrate) (012).

phase YSZ to that of the (012) reflection of $\alpha$ alumina substrate for the six samples after deposition at different temperatures.

From the SEM photograph shown in Fig. 4 (a), it seems that a dense YSZ film could be grown at a temperature as low as $700^{\circ} \mathrm{C}$. However, at $700^{\circ} \mathrm{C}$ it is expected that the bulk diffusion in the YSZ film should be the rate-limiting step because the bulk diffusion resistance in the YSZ film at $700^{\circ} \mathrm{C}$ is three to four orders of magnitude larger than that at $1000^{\circ} \mathrm{C}$ due to the large activation energy for electron conduction in YSZ $[14,15]$. Therefore the EVD film growth rate should be much smaller than 1.5 $\mu \mathrm{m} / \mathrm{hr}$ at $700^{\circ} \mathrm{C}$. By a more careful examination of the SEM photograph of the substrate after deposition at $700^{\circ} \mathrm{C}$ (see Fig. 4 (a)), it appears that the dense-film-like YSZ crystallites are deposited, during the initial CVD stage, in (not on) the top part of the pores of the substrate. This can be further substantiated by the XRD data discussed below.

The XRD patterns given in Fig. 5 for the substrate after deposition at $700^{\circ} \mathrm{C}$ reveal very strong reflections from $\alpha$-alumina but rather weak reflections from cubic phase YSZ. The values of the XRD intensity ratio $R[=I c(111) /$ 


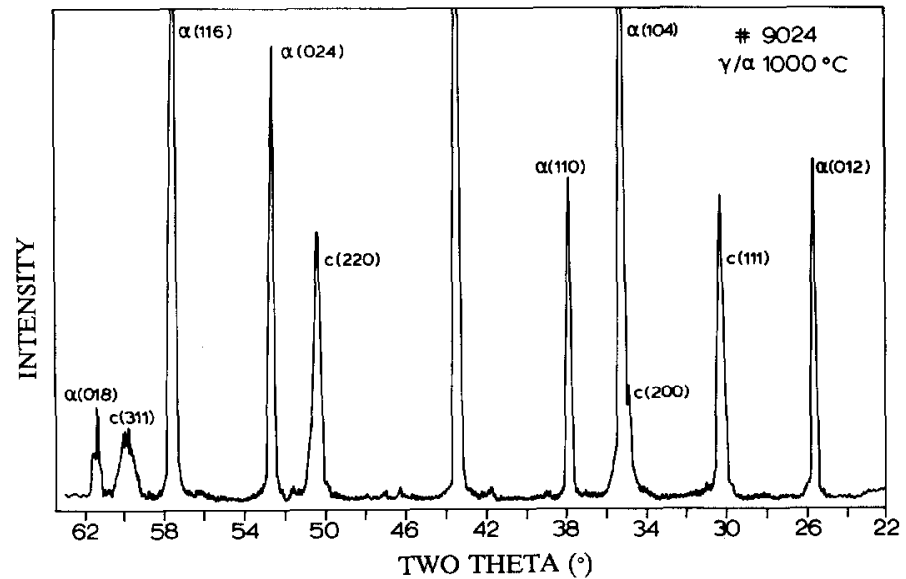

Fig. 5. XRD pattern of YSZ grown at $700^{\circ} \mathrm{C}$ on the coarse porous substrate ( $\alpha$-alumina) (indexed with "c" for cubic phase YSZ and " $\alpha$ " for $\alpha$-alumina).

$I \alpha(012)]$ listed in Table 3 for this substrate and the other two substrates after deposition at 800 and $850^{\circ} \mathrm{C}$ are all very small. Obviously, a smaller value of this $\mathrm{XRD}$ intensity ratio indicates a thinner YSZ film or less coverage of the deposited YSZ on the surface of a substrate. Therefore, the rather small values of $R$ for the three substrates after deposition at the lower temperatures suggest that there is a very thin or even no dense YSZ film on the surface of these substrates. The YSZ seen from the SEM photographs is mainly composed of YSZ crystallites deposited in the substrate pores very near the surface during the initial CVD stage.

When deposition temperature is higher, the XRD intensity ratio $R$ increases with deposition temperature, showing an increase in the coverage or thickness of the deposited films on the surface of the coarse pore substrate. This indicates that the growth of a somewhat thicker dense YSZ film on the substrate surface by the EVD process is possible only at the elevated temperatures because the EVD process relies on the electronic and ionic conductivities which are strongly temperature dependent.

Following similar experimental conditions as listed in Table 1, gas-tight YSZ films were also deposited on the top-layers of the membrane substrates. Because of the much smaller pore size of the top-layer, the pore closure time was typically ca. 5-10 min for deposition on the membrane substrates, shorter than that on the coarse pore substrates (30-45 min). With an additional 5-15 min deposition, ultrathin dense YSZ films were grown on the surface of the membrane substrate top-layers. Figure 6 is a SEM photograph showing the cross-section of one of such membrane substrates after deposition. As in the CVD stage some of the YSZ may be deposited inside the substrate top-layer which consists of ultrafine $\gamma$-alumina crystallites; the exact thickness of the dense YSZ film formed in the EVD stage on the top-layer is very difficult, if not impossible, to be estimated from the SEM photograph. Figure 7 gives an XRD pattern for one of the membrane substrates after deposition for 20 min and shows the existence of a cubic phase YSZ solid solution on the membrane substrate surface. The XRD reflections for $\alpha$-alumina, although already covered by a thin $\gamma$-alumina top-layer, are still very strong. This indicates that the grown YSZ film on the top layer of the substrate must be rather thin.

As discussed before, under the EVD experimental conditions listed in Table 1 , the film 


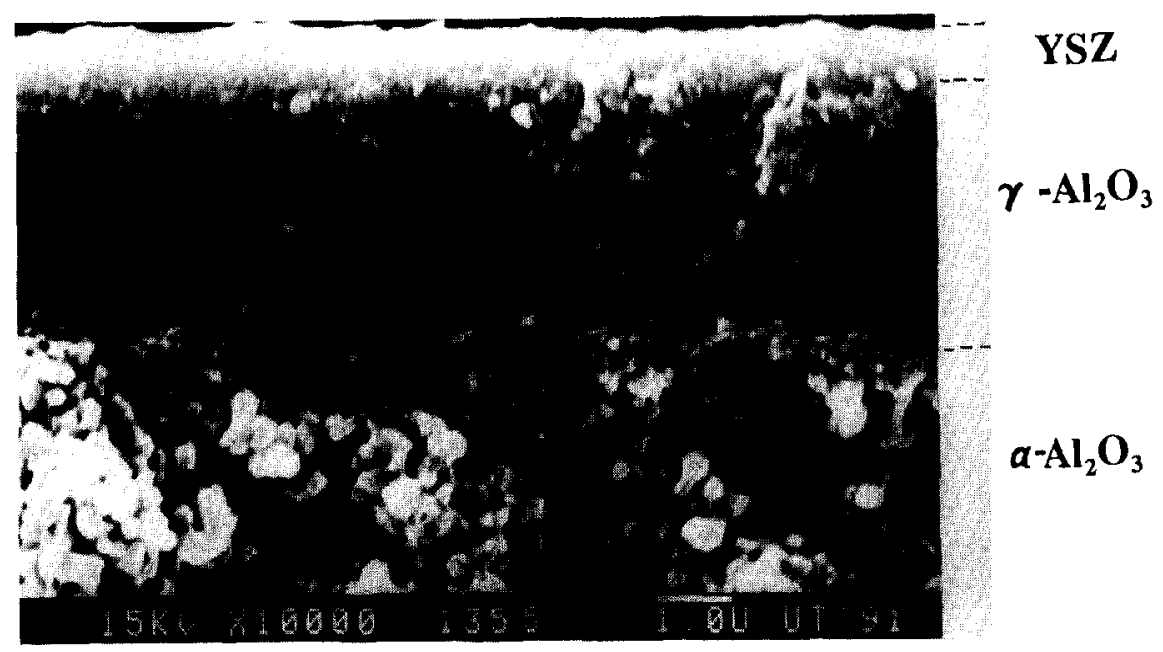

Fig. 6. SEM photograph of YSZ grown on the top-layer of the membrane substrate.

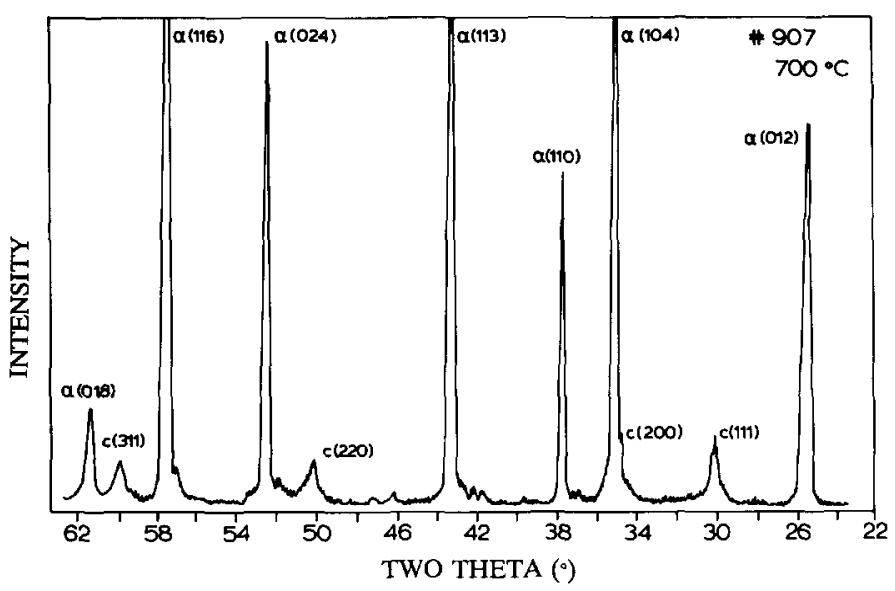

Fig. 7. XRD pattern of YSZ grown on the membrane substrate (the same samples as of Fig. 6) (indexed with "c" for cubic phase YSZ and " $\alpha$ " for $\alpha$-alumina).

growth rate is determined by the diffusion of the oxygen source reactant in the substrate pores. Since the diffusion resistance through the membrane substrate consisting of a very thin alumina top-layer and the coarse pore substrate is ca. $20 \%$ larger than that through the coarse pore substrate alone, the EVD film growth rate on the membrane substrates should be ca. $1.2 \mu \mathrm{m} / \mathrm{hr}, 20 \%$ percent smaller than that on the coarse pore substrate. Therefore from the film growth rate $(1.2 \mu \mathrm{m} / \mathrm{hr})$ and deposi- tion time after pore-closure (ca. $10 \mathrm{~min}$ ), a thickness of ca. $0.2 \mu \mathrm{m}$ can be estimated for the dense YSZ film deposited on the particular membrane substrate discussed here. An accurate experimental method is under development for the measurement of the dense film thickness on such a fine pore substrate. It is important to note that the membrane substrate deposited with such a thin YSZ film on the surface of its top-layer is impervious to $\mathrm{Ar}, \mathrm{He}$ and $\mathrm{N}_{2}$, as proven by the zero flux of these gases 
through the membrane composites (subject to a total pressure drop of 4 bar across the membrane).

It is found that the minimum thickness of a YSZ film which is gas-tight on a porous substrate strongly depends on the average pore size and pore size distribution of the substrate surface on which the film grows. As a rule of thumb, for a substrate with a reasonable uniform pore size distribution and porosity of ca. 0.5 , the minimum YSZ film thickness to be gas-tight should be roughly ca. 10 times the average pore diameter of the substrates. Therefore for the coarse pore substrates used in this study (pore diameter $=0.16 \mu \mathrm{m}$ ), a thickness of the YSZ film larger than $2 \mu \mathrm{m}$ can ensure the gas-tightness of the grown film. For the deposition of YSZ films on the top-layers of the membrane substrates (the top-layers have a pore diameter of $10 \mathrm{~nm}$, or slit pore width of $6 \mathrm{~nm}$ with a more uniform pore size distribution), the minimum gas-tight thickness can be as small as 60-100 $\mathrm{nm}$. Therefore ultrathin gas-tight YSZ films can be grown only on these membrane substrates.

\section{Oxygen permeation}

A negative pressure change in the oxygenchamber was found for all the in-situ oxygen permeation experimental runs after deduction of leakage. For the mixture of air/steam as the permeating gas, the pressure drop in the oxygen-chamber is more rapid in the initial period and becomes constant ca. 10-20 min after the introduction of the permeating gas in the oxygen-chamber, as shown in Fig. 3. If the initial slopes of the pressure drop data are used to calculate the permeation flux, the air/steam mixture gives a much larger permeation flux than the air. However, it is found that the initial slopes of the pressure change data for air/steam mixture, as shown in Fig. 8, decrease with increasing temperature. This indicates that the pressure drop for the air/steam mixture in the initial period is due not only to the oxygen per- meation but also to some other phenomena such as adsorption of water vapor on the internal surface of the oxygen-chamber. In most cases, it was found that the pressure drop for air/ steam mixture became constant about $30 \mathrm{~min}$ after the introduction of the permeating gas in the oxygen chamber. Therefore the pressure change data at the steady-state were used, as shown in Fig. 9, for calculating the oxygen permeation flux with air/steam mixture as the permeating gas. For air the steady-state of the pressure change rate was reached as soon as the permeating gas was introduced. To give an example, Fig. 10 shows the pressure changes as a function of time in the oxygen-chamber with air as the permeating gas at different temperatures.

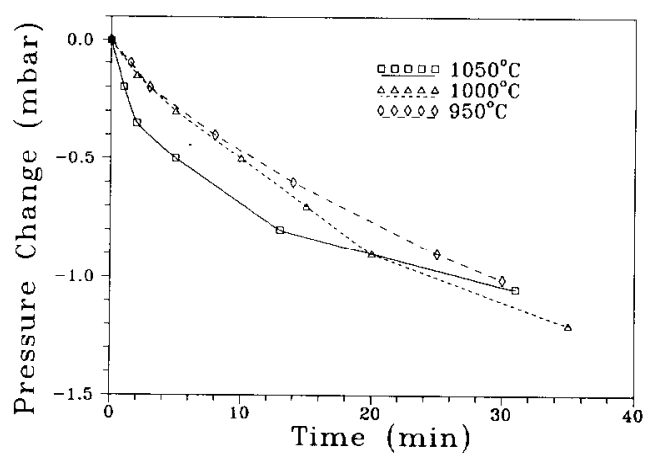

Fig. 8. Pressure drop in the oxygen-chamber for air/steam in the initial period of permeation experimental runs.

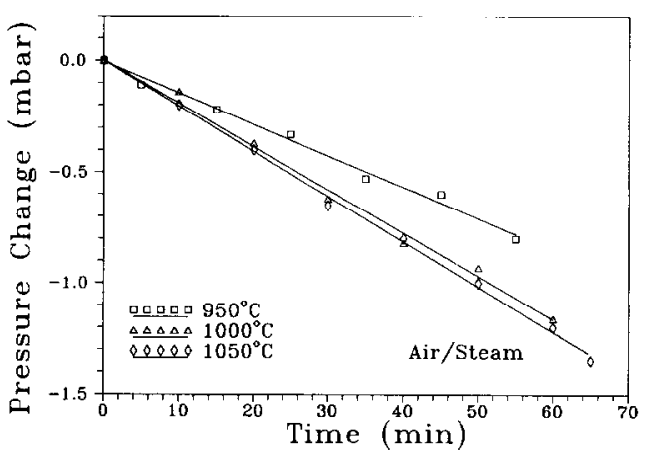

Fig. 9. Pressure change for air/steam in the oxygen-chamber at different temperatures. 


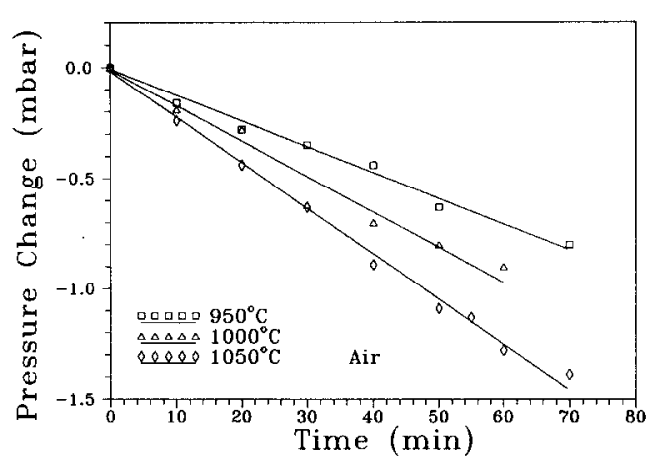

Fig. 10. Pressure change for air in the oxygen-chamber at different temperatures.

TABLE 4

Oxygen permeation flux through YSZ films grown on the coarse porous substrates

\begin{tabular}{lclcc}
\hline $\begin{array}{l}\text { Sample } \\
\#\end{array}$ & $\begin{array}{l}\text { Permeation } \\
\text { temp }\left({ }^{\circ} \mathrm{C}\right)\end{array}$ & $\begin{array}{l}\text { Thickness of }(\mu \mathrm{m}) \\
\text { YSZ }\end{array}$ & $\begin{array}{l}\text { Permeation flux } \\
\left(10^{-9} \mathrm{~mol} / \mathrm{cm}^{2}-\right. \\
\text { sec })\end{array}$ \\
\cline { 3 - 5 } & & & Air & Air/steam \\
\hline 9015 & 950 & 5 & 3.54 & 5.65 \\
& 1000 & 5 & 8.76 & 11.6 \\
& 1050 & 5 & 15.6 & 14.9 \\
9026 & 1000 & 4 & 12.4 & 19.1 \\
9063 & 1000 & 5 & 14.6 & 38.8 \\
9022 & 1000 & 3.5 & 10.7 & - \\
9032 & 1000 & 6 & 9.4 & - \\
\hline
\end{tabular}

The oxygen permeation fluxes are calculated from the slopes of the pressure change data as shown in Figs. 9 and 10 by:

$J_{\mathrm{O}_{2}}=\left(V_{\mathrm{r}} / R T_{\mathrm{r}} S\right)(-\mathrm{d} P / \mathrm{d} t)$

where $V_{\mathrm{r}}$ is the volume of the oxygen-chamber $\left(375 \mathrm{~cm}^{3}\right) ; T_{\mathrm{r}}$ is the average temperature in the oxygen-chamber $(363 \mathrm{~K}) ; R$ the gas constant and $S$ the permeating area of the membrane composite $\left(0.5 \mathrm{~cm}^{2}\right)$. The measured oxygen permeation fluxes on the YSZ film supported on the coarse porous substrates are summarized in Table 4 . The determined oxygen permeation flux at $1000^{\circ} \mathrm{C}$ for different samples ranges from $8.7 \times 10^{-9}$ to $14.6 \times 10^{-9} \mathrm{~mol} / \mathrm{cm}^{2}$ - sec for air and $11.6 \times 10^{-9}$ to $38.8 \times 10^{-9} \mathrm{~mol} /$ $\mathrm{cm}^{2}$-sec for air/steam mixture. The leakage flux in most cases is ca. $10 \%-20 \%$ of the total flux measured. Therefore the accuracy of the oxygen permeation flux measured should be within $\pm 20 \%$. Assuming the pore diffusion being the rate-limiting step, the oxygen flux through the coarse porous substrate under the conditions of oxygen permeation measurements $\left(P_{\mathrm{O}_{2}}^{\prime \prime}=0.03\right.$ atm and $P_{\mathrm{O}_{2}}^{\prime}<10^{-5}$ atm, $T=1000^{\circ} \mathrm{C}$ where $P_{\mathrm{O}_{2}}^{\prime}$ and $P_{\mathrm{O}_{2}}^{\prime \prime}$ are the oxygen partial pressure in the oxygen-chamber and the chloride-chamber respectively) is ca. $110 \times 10^{-9} \mathrm{~mol} / \mathrm{cm}^{2}-\mathrm{sec}$, five to ten times larger than the permeation flux measured on the composites as listed in Table 4. Therefore, the pore diffusion is not the rate limiting step under the conditions of the oxygen permeation experiments.

The measured oxygen permeation fluxes for these YSZ composites listed in Table 4 are much larger than the literature data for the thicker YSZ pellets at somewhat different experimental conditions [12-16]. Some of the published data of free-electron and hole conductivities calculated from the oxygen permeation data of relatively thicker YSZ pellets [14,15] are given in Table 5. The oxygen permeation flux data published for the thicker YSZ pellets can be extrapolated to the present experimental conditions using these electronic conductivity data with the following equation which is derived based on the assumption of bulk electrochemical transport being the rate-limiting step [11]:

$$
\begin{gathered}
J_{\mathrm{O}_{2}}=\left(R T / L F^{2}\right)\left\{\sigma_{\mathrm{p}}^{\mathrm{o}}\left[\left(P_{\mathrm{O}_{2}}^{\prime}\right)^{1 / 4}-\left(P_{\mathrm{O}_{2}}^{\prime \prime}\right)^{1 / 4}\right]\right. \\
\left.+\sigma_{\mathrm{n}}^{\mathrm{o}}\left[\left(P_{\mathrm{O}_{2}}^{\prime \prime}\right)^{-1 / 4}-\left(P_{\mathrm{O}_{2}}^{\prime}\right)^{-1 / 4}\right]\right\}
\end{gathered}
$$

where $\sigma_{\mathrm{p}}^{\mathrm{o}}$ and $\sigma_{\mathrm{n}}^{\mathrm{o}}$ are the electronic-hole and free-electron conductivities; $F$ the Faraday constant; $T$ the temperature; $L$ the thickness of YSZ; $P_{\mathrm{O}_{2}}^{\prime}$ and $P_{\mathrm{O}_{2}}^{\prime \prime}$ are again the oxygen partial pressures in the higher pressure side (in the oxygen-chamber) and lower pressure side (in the chloride-chamber). The oxygen permeation 
TABLE 5

Previous oxygen permeation experiments on YSZ and extrapolated permeation fluxes

\begin{tabular}{|c|c|c|}
\hline Investigators & Park \& Blumenthal [15] & Kleitz et al. [14] \\
\hline Electrolyte & $8 \mathrm{~m} / \mathrm{o}$ YSZ & $9 \mathrm{~m} / \mathrm{o} Y S Z$ \\
\hline Disk thickness (mm) & 1.5 & $3-3.6$ \\
\hline Temperature $\left({ }^{\circ} \mathrm{C}\right)$ & $800-1050$ & $1170-1550$ \\
\hline \multicolumn{3}{|c|}{$\sigma_{\mathrm{n}}^{\circ}\left(\mathrm{ohm}^{-1}-\mathrm{cm}^{-1}-\mathrm{atm}^{-1 / 4}\right)$} \\
\hline -general formula & $1 / 3 \times 10^{7} \mathrm{e}^{-3.88 \mathrm{ev} / K T}$ & $5.5 \times 10^{5} \mathrm{e}^{-3.72 \mathrm{ev} / K T}$ \\
\hline -at $1000^{\circ} \mathrm{C}$ & $5.8 \times 10^{9}$ & $1.0 \times 10^{-9}$ \\
\hline \multicolumn{3}{|l|}{$\sigma_{\mathrm{n}}^{\mathrm{o}}\left(\mathrm{ohm} \mathrm{m}^{-1}-\mathrm{cm}^{-1}-\mathrm{atm}^{1 / 4}\right)$} \\
\hline -general formula & $2.3 \times 10^{2} \mathrm{e}^{-1.67 \mathrm{ev} / K T}$ & $1.4 \times 10 \mathrm{e}^{-1.52 \mathrm{ev} / K T}$ \\
\hline -at $1000^{\circ} \mathrm{C}$ & $5.7 \times 10^{-5}$ & $1.6 \times 10^{-5}$ \\
\hline \multicolumn{3}{|l|}{ Extrapolated permeation } \\
\hline flux $\left(\mathrm{mol} / \mathrm{cm}^{2}-\mathrm{sec}\right)^{a}$ & $4.8 \times 10^{-8}$ & $1.4 \times 10^{-8}$ \\
\hline
\end{tabular}

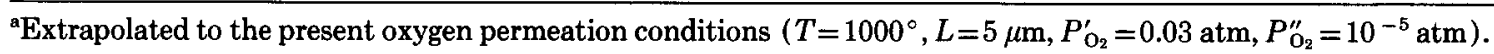

fluxes measured in the present study (listed in Table 4) agree reasonably well with the extrapolated data given in Table 5 . If the surface reaction rate coefficients measured by Dou et al. [16] for calcia-stabilized zirconia is used to predict the oxygen permeation flux under the present conditions, a value of ca. $1.3 \times 10^{-11}$ $\mathrm{mol} / \mathrm{cm}^{2}$-sec is obtained assuming the surface reaction being the rate-limiting step. This is three orders of magnitude smaller than the experimentally measured data presented in Table 4. It should be pointed out that the results of Dou et al. were obtained for the thicker zirconia pellets under much higher oxygen partial pressures compared to the present experiments. Therefore the surface reaction may not be the rate-limiting step for the very thin YSZ films prepared by EVD under the current experimental conditions.

The average YSZ film growth rate during EVD film growing experiments is ca. $1.5 \mu \mathrm{m} /$ $\mathrm{hr}$ at $1000^{\circ} \mathrm{C}$, which is equivalent to an oxygen permeation flux of ca. $1 \times 10^{-9} \mathrm{~mol} / \mathrm{cm}^{2}$-sec. This value is 5 to 10 times smaller than the permeation fluxes reported in Table 4. This difference is mainly due to the different oxygen partial pressure in the oxygen-chamber and the chloride-chamber between the EVD film growth experiments and the in-situ oxygen permeation experiments, as seen in Table 1. It is known that the oxygen permeation flux through an YSZ composite is proportional to $P_{\mathrm{O}_{2}}$ with the pore diffusion as the rate-limiting step and roughly to $\left(P_{\mathrm{O}_{2}}^{\prime}\right)^{1 / 4}$ with the bulk electrochemical transport as the rate-limiting step [11]. Therefore the difference in the oxygen partial pressures between these two types of different experiments may result in a different rate-limiting step for each type of experiment. The calculated oxygen permeation fluxes, assuming the pore diffusion or bulk diffusion being the ratelimiting step and using the method proposed by Lin et al. [11], are presented in Table 6 for these two types of experiments. The step which gives the smaller predicted oxygen flux should be the rate-limiting step. In the oxygen permeation experiments, the rate-limiting step is the bulk electrochemical transport in the grown YSZ film. During the EVD film growing experiments the pore diffusion becomes the rate-limiting step because of the lower $P_{\mathrm{O}_{2}}$ in both reactor chambers. The experimentally measured oxygen fluxes in these two kinds of the experiments agree with the oxygen flux predicted for the EVD film growing experiments (assuming the pore diffusion being the rate-limiting step) 


\section{TABLE 6}

Comparison of oxygen permeation flux through YSZ film during EVD film growing and oxygen permeation measurements

\begin{tabular}{|c|c|c|}
\hline & $\begin{array}{l}\text { EVD film } \\
\text { growing }\end{array}$ & $\begin{array}{l}\text { Oxygen } \\
\text { Permeation }\end{array}$ \\
\hline $\begin{array}{l}P_{\mathrm{O}_{2}} \text { in oxygen-chamber } \\
\quad(\text { atm })\end{array}$ & $6 \times 10^{-4}$ & $3 \times 10^{-2}$ \\
\hline $\begin{array}{l}P_{\mathrm{O}_{2}} \text { in chloride- } \\
\text { chamber (atm) }\end{array}$ & $<10^{-14}$ & $<10^{-5}$ \\
\hline $\begin{array}{l}\text { Pore diffusion } \\
\text { controlled } J_{\mathrm{O}_{2}}^{a}\end{array}$ & $2 \times 10^{-9}$ & $1 \times 10^{-7}$ \\
\hline $\begin{array}{l}\text { Bulk diffusion } \\
\text { controlled } J_{\mathrm{O}_{2}}^{a}\end{array}$ & $>6 \times 10^{-9}$ & $\sim 1.5 \times 10^{-8}$ \\
\hline $\begin{array}{l}\text { Experimental } \\
\text { measured } J_{\mathrm{O}_{2}}^{a}\end{array}$ & $\sim 1.0 \times 10^{-9}$ & $\sim 1 \times 10^{-8}$ \\
\hline
\end{tabular}

aUnit: $\left(\mathrm{mol} / \mathrm{cm}^{2}\right.$-sec $)$

TABLE 7

The oxygen permeation fluxes with air as permeating gas through YSZ films grown on membrane substrates $\left(1000^{\circ} \mathrm{C}\right)$

\begin{tabular}{llll}
\hline $\begin{array}{l}\text { Sample } \\
\#\end{array}$ & $\begin{array}{l}\text { Deposition } \\
\text { time } \\
(\mathrm{min})\end{array}$ & $\begin{array}{l}\text { Estimated } \\
\text { YSZ thickness } \\
(\mu \mathrm{m})\end{array}$ & $\begin{array}{l}\text { Permeation flux } \\
\left(10^{-9} \mathrm{~mol} /\right. \\
\left.\mathrm{cm}^{2}-\mathrm{sec}\right)\end{array}$ \\
\hline 9037 & 10 & 0.2 & 20.9 \\
9038 & 30 & 0.5 & 55.3 \\
9040 & 30 & 0.5 & 55.3 \\
9048 & 30 & 0.5 & 31.5 \\
9052 & 30 & 0.5 & 17.1 \\
\hline
\end{tabular}

and for the oxygen permeation (assuming bulk diffusion being the rate-limiting step). The EVD film growth data and the oxygen permeation data are in general consistent to each other. This further supports that for such YSZ films prepared by the EVD method the oxygen permeation flux is indeed at least larger than $1 \times 10^{-9} \mathrm{~mol} / \mathrm{cm}^{2}-\mathrm{sec}$ under the experimental conditions investigated.

The oxygen permeation fluxes through the YSZ films grown on the membrane substrates were also measured in-situ using air as the permeating gas under the same conditions as those used for the oxygen permeation measurements for YSZ deposited on the coarse porous substrates. The results are summarized in Table 7. As mentioned before, the exact thickness of the deposited dense YSZ films on the membrane substrates was difficult to measure. Furthermore, slight pre-deposition or post-deposition before or after introduction or termination of oxygen source reactant during the EVD film growing process may also make it difficult to accurately predict the exact film thickness in the current experiments. Nevertheless, it is acceptable that the YSZ films grown on the membrane substrates should be thinner than those grown on the coarse porous substrates because of the shorter deposition time. Due to the smaller thickness of YSZ films, the oxygen permeation fluxes through the YSZ films on the membrane substrates, as listed in Table 7, are generally larger than those through YSZ on the coarse porous substrates presented in Table 4. These results further show that under the experimental conditions for oxygen permeation measurements the surface reaction obviously does not play a dominant role. The bulk electrochemical transport in such thin YSZ films is the rate-limiting step. This suggests that a further decrease in the YSZ film thickness, which, of course, should remain gas-tight, may further raise the oxygen permeation flux.

It can be also found in Table 4 that the oxygen permeation fluxes for air/steam mixture, in most cases, are larger than those for air. Furthermore, the activation energy calculated from the data of Run \# 9015 using the Arrhenius plot for air/steam mixture $(130 \mathrm{~kJ} / \mathrm{mol})$ is about two third of that for air $(198 \mathrm{~kJ} / \mathrm{mol})$. This suggests that addition of water vapor to the air may enhance the oxygen permeation flux and reduce the activation energy for oxygen permeation. It is also found that the YSZ film growth rate with dried air or pure oxygen is much slower than that with humid air, air/ 
steam mixture or oxygen/steam as the oxygen source reactant, as listed in Table 2. Water may play a similar role in enhancing the oxygen flux in the both cases. Although some researchers [20] have noticed that water vapor may increase both the surface reaction rate and bulk diffusion of the oxygen transport in solid oxide electrolytes, the exact mechanism of the oxygen permeation with water vapor through the YSZ is an interesting topic for further research. It should be pointed out that the EVD apparatus used in this study was not originally designed for the oxygen permeation experiments. The apparatus limitation, therefore, made it difficult to investigate more accurately and comprehensively the oxygen permeation phenomena for such EVD prepared membrane composites with thin YSZ films. Nevertheless, the work reported here, to our best knowledge, represents the first effort on investigating the oxygen permeation through solid electrolyte films with a thickness thinner than $10 \mu \mathrm{m}$.

\section{Conclusions}

Ceramic membranes consisting of a gas-tight thin YSZ film with a thickness ranging from 0.2 to $5 \mu \mathrm{m}$ on top of a porous alumina ceramic support can be prepared by the EVD method. The minimum gas-tight thickness of the YSZ films depends strongly on the average pore size of the substrates on which the films are deposited. Gas-tight YSZ films thinner than $1 \mu \mathrm{m}$ can be grown on the two-layer membrane substrates consisting of a thin $\gamma$-alumina top layer with improved thermal stability. The rate-limiting step during the EVD film growing process under the present film growing experimental conditions and the specific supports used is the diffusion of the oxygen source reactant in the substrate pores.

Oxygen permeation through the supported YSZ films grown by the EVD method was insitu investigated on the EVD apparatus which avoided possible high temperature sealing problems and sample transferring inconvenience if performed in a specially designed permeation apparatus. The oxygen permeation fluxes through such YSZ membrane composites are in the range of $3 \times 10^{-9}$ to $6 \times 10^{-8} \mathrm{~mol} /$ $\mathrm{cm}^{2}$-sec, which is much larger than the literature data for thicker YSZ pellets. The literature data of the oxygen permeation extrapolated to the present experimental conditions assuming bulk diffusion being the rate-limiting step, however, agree well with the oxygen permeation data reported in this study. The oxygen permeation fluxes through the thinner YSZ films supported on the membrane substrates are larger than those through the thicker YSZ films grown on the coarse porous substrates. These results suggest that during the oxygen permeation experiments the rate-limiting step is the bulk electrochemical transport in the grown YSZ films. Furthermore, addition of water vapor in air enhances the oxygen permeation flux and reduces the activation energy for oxygen permeation.

\section{Acknowledgement}

This investigation was supported by the Dutch Ministry of Economical Affairs (IOP Technical Ceramics No. 87 A045). Mr. J. Meijerink and Ir. G. Polhaar are acknowledged for the assistance in running the experiments.

\section{List of symbols}

F Faraday constant

$J_{\mathrm{O}_{2}}$ oxygen permeation flux ( $\left.\mathrm{mol} / \mathrm{cm}^{2}-\mathrm{sec}\right)$

$L$ thickness of substrate disk or layer ( $\mathrm{mm}$ or $\mu \mathrm{m}$ )

$P \quad$ pressure in the oxygen-chamber (atm)

$P_{\mathrm{O}_{2}}^{\prime \prime}$ oxygen partial pressure at the lower pressure side (atm)

$P_{\mathrm{O}_{2}}^{\prime}$ oxygen partial pressure at the higher pressure side (atm) 
$R \quad$ gas constant

$S$ permeation area of the substrate disk $\left(\mathrm{cm}^{2}\right)$

$t \quad$ time (sec or $\min$ )

$T_{\mathrm{r}}$ average temperature of the oxygen-chamber $\left({ }^{\circ} \mathrm{C}\right.$ or $\left.\mathrm{K}\right)$

$T$ permeation temperature $\left({ }^{\circ} \mathrm{C}\right.$ or $\mathrm{K}$ )

$V_{\mathrm{r}}$ volume of the oxygen-chamber $\left(\mathrm{cm}^{3}\right)$

$\sigma_{n}^{\circ}$ free-electron conductivity in the EVD YSZ film at one atm of oxygen partial pressure (ohm ${ }^{1}-\mathrm{cm}^{-1}$-atm ${ }^{-1 / 4}$ )

$\sigma_{\mathrm{p}}^{\mathrm{o}}$ hole conductivity in the EVD YSZ film at one atm of oxygen partial pressure $\left(\mathrm{ohm}^{-1}-\mathrm{cm}^{-1}-\mathrm{atm}^{1 / 4}\right)$

\section{References}

1 A.J. Burggraaf, H.J.M. Bouwmeester, B.A. Boukamp and V. Zaspalis, Synthesis, microstructure and properties of porous and dense ceramic membranes, in: $\mathrm{J}$. Nowotny (Ed.), Science of Ceramic Interfaces, Elsevier, Amsterdam, 1991, in press.

2 A.O. Isenberg, Growth of refractory oxide by electrochemical vapor deposition (EVD) at elevated temperature, in: J.D.E. Mc Intyre, S. Srinavasan and F.G. Will (Eds.), ECS Symp. Electrode Materials, Processes for Energy Conversion and Storage, Electrochem Soc. Inc., Princeton, NJ, 77-6 (1977) 572.

3 Y.S. Lin, P. Fransen, K.J. de Vries and A.J. Burggraaf, Experimental study on CVD modification of ceramic membranes, Proc. 11th Int. CVD Conf., K.E. Spear and G.W. Cullen (Eds.), The Electrochem. Soc., Pennington, NY, 1990, p. 539.

4 Y.S. Lin and A.J. Burggraaf, Modelling and analysis of CVD processes in porous media for ceramic composite preparation, Chem. Eng. Sci., 46 (1991) 3067.

5 P. Kofstad, High-Temperature Oxidation of Metals, Wiley, New York, NY, 1966, Chap. 5, pp. 112-146.

6 L. Heyne, Electrochemistry of mixed ionic-electronic conductors, in: S. Geller (Ed.), Solid Electrolytes, Springer-Verlag, Berlin, 1977, p. 169.

7 G. Dietrich and W. Schäfer, Advances in the development of thin film cells for high temperature electrolysis, Int. J. Hydrogen Energy, 9 (1984) 747.
8 M.F. Carolan and J.M. Michaels, Growth rates and mechanism of electrochemical vapor deposited yttria stabilized zirconia films, Solid State Ionics, 37 (1990) 189.

9 U.N. Pal and S.C. Singhal, Electrochemical vapor deposition of yttria stabilized zirconia films, J. Electrochem. Soc., 137 (1990) 2937.

10 N.J. Kiwiet and J. Schoonman, Electrochemical vapor deposition: theory and experiment, Proc. 25th Int. Soc. Energy Conversion Eng. Conf., P.A. Nelson et al. (Eds. ), AIChE, New York, NY, 1990, p. 240.

11 Y.S. Lin, L.G.J. de Haart, K.J. de Vries and A.J. Burggraaf, A kinetic study of the electrochemical vapor deposition of solid oxide electrolyte films on porous substrates, J. Electrochem. Soc., 137 (1990) 3960.

12 S.F. Palguev, V.K. Gilderman and A.D. Neujmin, Oxygen permeability of stabilized zirconia solid electrolyte, J. Electrochem. Soc., 122 (1975) 747.

13 J. Fouletier, P. Fabry and M. Kleitz, Electrochemical semipermeability and the electrode microsystems in solid oxide electrolyte cells, J. Electrochem. Soc., 123 (1976) 204.

14 M. Kleitz, E. Fernandez, J. Fouletier and P. Farby, Determination of electronic conductivities and ionic domains of $\mathrm{ZrO}_{2}-\mathrm{Y}_{2} \mathrm{O}_{3}$ by semipermeability measurements, Adv. Ceram., 3 (1981) 349.

15 J.H. Park and R.N. Blumenthal, Electronic transport in 8 molar percent $\mathrm{ZrO}_{2}-\mathrm{Y}_{2} \mathrm{O}_{3}$, J. Electrochem. Soc., 136 (1989) 2867.

16 S. Dou, C.R. Masson and P.D. Paccy, Mechanism of oxygen permeation through lime-stabilized zirconia, J. Electrochem. Soc., 132 (1985) 1843.

17 Y.S. Lin, L.G.J. de Haart, K.J. de Vries and A.J. Burggraaf, Modification of ceramic membranes by CVD and EVD for gas separation, catalysis and SOFC application, in: G. de With, R.A. Terpstra and R. Metselaar (Eds.), Euro-Ceramics, Vol. 3-Engineering Ceramics, Proc. 1st Eur. Ceramic Soc. Conf., Maastricht, June 18-3, 1989, Elsevier, Amsterdam, 1989, pp. 590-95.

18 L.G.J. de Haart, Y.S. Lin, K.J. de Vries and A.J. Burggraaf, Modified-CVD of nanoscale structure in and EVD of thin layers on porous ceramic membranes, J. Europ. Ceram. Soc., 8 (1991) 59.

19 Y.S. Lin and A.J. Burggraaf, Preparation and characterization of high-temperature thermally stable alumina composite membranes, J. Am. Ceram. Soc., 74 (1991) 219.

20 V.S. Stotz and C. Wagner, Die Löslichkeit von Wasserdampf und Wasserstoff in festen Oxiden, Ber. Bunsenges., 70 (1966) 780 . 